\title{
Kinetic Theory Model Predictions Compared with Low-Thrust Axisymmetric Nozzle Plume Data
}

\author{
B. R. Riley and S. J. Fuhrmant \\ University of Evansville, Evansville, Indiana \\ and \\ P. F. Penko* \\ NASA-Lewis Research Center, Cleveland, Ohio
}

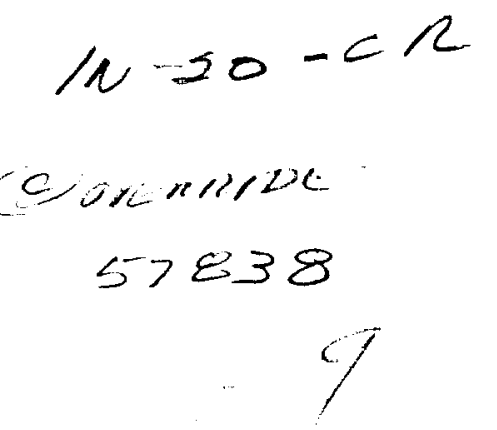

\begin{abstract}
A system of nonlinear integral equations equivalent to the steadystate Krook kinetic equation was used to model the flow from a low-thrust axisymmetric nozzle. The mathematical model was used to numerically calculate the number density, temperature, and velocity of a simple gas as it expands into a near vacuum. With these quantities the gas pressure and flow directions of the gas near the exit plane were calculated and compared with experimental values for a low-thrust nozzle of the same geometry and mass flow rate.
\end{abstract}

\section{Introduction}

A coordinated program to study gas flows from low-thrust nozzles $(.1 \mathrm{~N})$ is in progress at NASA-Lewis Research Center.' This effort includes numerical mathematical modeling and experimental measurements to determine plume parameters.

In two previous papers, model results were presented for plume flows from a two-dimensionak nozzle and a three-dimensional axisymmetric nozzle. No comparison of the model results were made with experimental data. In this paper, for the first time, the model results and experimental data are compared. The two earlier papers showed the feasibility of utilizing the Boltzmann ${ }^{4}$ equation with a Krook-type relaxation s scattering term for binary collisions to model plume flows for low-thrust nozzles when the flow goes through the transition region (continuum to freemolecular flow). In particular, it was demonstrated that an iterative process for solving the Boltzmann equation would converge to give a steady-state solution using a reasonable amount of computer time. The spherical computational volume was quite small $(-3 \mathrm{~cm}$ radius) and the nozzles at the exit plane were only $3 / 4 \mathrm{~cm}$ in diameter.

The model work described here is for a larger nozzle (exit plane diameter $-3.2 \mathrm{~cm})$ and extends the computational volume $(-20 \mathrm{~cm}$ radius)

Copyright $\odot 1993$ by American Institute of Aeronautics and Astronautics, Inc. All rights reserved.

"Professor and Chair, Department of Physics

+Undergraduate Student, Department of Physics

₹Aerospace Engineer, Member AIAA 
in an attempt to predict parameters in the near and intermediate regions of the plume. The nozzle geometry and propellant flow rate in the experimental setup are identical to those assumed in the model, thus model predictions can be directly compared with the experimental measurements.

\section{KInetic Theory Model}

\section{Mathematical Formulation}

The Krook kinetic equation ${ }^{5}$ or iterate equation " for steady-state flow that was solved numerically by integrating over velocity space along a characteristic line is

$$
\text { v. } \nabla_{f} f(v, r)=A\left(n d\left(n f_{0}-f\right)\right.
$$

where $f_{0}$ (shown below) is an equilibrium Maxwellian velocity distribution normalized to one at a given $r$.

$$
f_{0}=\left\{1 /(2 \pi k T)^{3 / 2}\right\} \exp -\left\{\left(m /(2 k T)(v-u)^{2}\right\}\right.
$$

The boundary conditions for $f$ (probability distribution function) are discussed in the next section of this paper.

The first iteration values for $n(r), u(r)$, and $T(r)$ (number density, mean velocity, and temperature) at each grid point can then be calculated using the following definitions

$$
\begin{gathered}
n(r)=\iiint f(r, v) d^{3} v \\
u(r)=(1 / n) \iiint v_{f}(r, v) d^{3} v \\
\pi(r)=\{m /(3 k T n)\} \iiint(v-u)^{2} f(r, v) d^{\beta} v
\end{gathered}
$$

The values of $n, u$, and $T$ are put into Eqs. (1) and (2) and the process $^{3}$ is repeated until convergence is obtained. At convergence the values for $n, u$, and $T$ at the grid points do not significantly change from the values obtained in the previous iteration. Because the nozzle is axisymmetric, only parameter values in one plane through the axis of symmetry are necessary. Figure 1 shows the plane polar grid system used in the model calculations.

\section{Nozzle Parameters and Flowfield Boundary Conditions}

As mentioned earlier the experimental flow conditions and nozzle geometry were identical with those in the model. The nozzle was axisymmetric with a half angle at the exit plane of $20 \mathrm{deg}$. The nozzle throat diameter was $3.18 \mathrm{~mm}$ and the area ratio (exit/throat) was 100 . The plume gas was $\mathrm{N}_{2}$ with a flow rate of $6.8 \times 10^{5} \mathrm{~kg} / \mathrm{s}$.

To simulate the $0.02 \mathrm{~Pa}$ experimental background pressure in the vacuum chamber, the plume in the model was assumed to expand into a background number density set at $1.2 \times 10^{18} \mathrm{~N}_{2}$ molecules $/ \mathrm{m}^{3}$ with a temperature of $300 \mathrm{~K}$ at zero mean velocity. This was accomplished in the model by assuming experimental vacuum chamber conditions for the surface located at $200 \mathrm{~mm}$ with angles from the center line greater than 50 deg (See Fig. 1). For the surface at $200 \mathrm{~mm}$ in the first 50 deg from the centerline, the flow was assumed to have only an outward velocity component.

The flow parameters at the nozzle exit plane used for the inflow 
boundary conditions were obtained from Boyd ar who utilized a discrete simulation Monte Carlo (DSMC) computational method to model the flow inside the nozzle. Boyd's model assumes diffuse scattering along the inside of the nozzle wall. Thus the boundary layer effect on the flow external to the nozzle will be inherent through the exit surface boundary conditions. The parameters at exit surface grid points are given in Table 1. Boundary conditions for the external wall of the nozzle were modeled with $f=0$.

\section{Convergence Criterlon and Computer Time}

The convergence to a solution for the iteration process was assumed when changes in the quantities $n, u$, and $T$ compared to previous iteration values approached zero. A solution for the 539 grid points shown in Fig. 1 took approximately $20 \mathrm{~h}$ of CPU time on the CRAY -XMP at the NASA-Lewis Research Center. An equivalent solution was obtained with about $1 / 2$ the number of grid points and correspondingly less computer time. Most of the computer time was taken in the relatively high-number density regions near the nozzle exit plane and along the radii lines at large angles (angle $>50 \mathrm{deg}$ ) where the number density is near the background level.

For convergence at a grid point, ctest, defined to be the square root of the sum of the squares of the fractional changes in the number density, the components of velocity, and the temperature was required to be small. Typically the convergence criterion for ctest was <0.01. A correction factor that ranged from 1.0 to 1.1 as $r$ in Fig. 1 ranged from 46.4 $\mathrm{mm}$ to $200 \mathrm{~mm}$ was applied to the number density to insure that the mass flow rate at each radius was maintained at $\sim 6.8 \times 10^{-5} \mathrm{~kg} / \mathrm{s}$. This correction was needed when the grid point separations were large.

\section{Experimental Data}

The experimental data used in this paper were taken in a vacuum tank for space-simulated tests at NASA-Lewis Research Center. The details of the experimental setup are described in a paper by Penko $^{8}$ et al. and the correction factor that was applied to the pressure measurements due to the shock wave caused by the measuring probe is discussed by Shapiro. ${ }^{\circ}$ A conical probe was used to measure the flow angles and Pitot tubes with diameters of $1 \mathrm{~mm}$ and $6.4 \mathrm{~mm}$ were used to measure the total pressure in appropriate regions of the plume. The $1-\mathrm{mm}$ tube was used near the exit plane where large pressure gradients exist and the 6.4-mm tube was used in the far-field region of the plume. An overall measurement accuracy in the pressure measurements of $\pm 9 \%$ was estimated at the exit plane. This improved to $\pm 2 \%$ in the far field. The 30 -deg conical probe used to measure the flow angle in the farfield was $6.4 \mathrm{~mm}$ in diameter at the base and had an estimated accuracy of \pm 1 deg.

\section{Model Results Compared with Experimental Data}

\section{Model Prediction Overview and Parameter Manipulations}

The model results are depicted in contour plots for the grid points as seen in Fig. 1 with the exclusion of the grid points that have $r$ values less than $46.4 \mathrm{~mm}$. Figures 2.5 are contour plots for the number density, axial component of velocity, radial component of velocity, and temperature, respectively. These plots give a complete visual perspective of the model results. The contour plot in Fig. 6 shows the Pitot pressures as calculated 
from the model which can be compared directly with the data.

Pitot pressures were calculated from the model values of $n, u$, and $T$ at the grid points with shock wave and supersonic rarefied flow effects built into the model results. Since the Pitot probe acts as an intrusive device around which a shock wave develops in the supersonic flow, the pressure drop across the shock wave must be calculated in order to compare with the experimental data. Thus, the Rayleigh supersonic Pitottube formula ${ }^{\circ}$ was applied to the model prediction for pressure.

A second modification to the model prediction for pressure was necessary due to the rarefied nature of the flow. The following equation 1.10 was applied to the model results

$$
\log \left(P_{\text {om }} / P_{\text {oy }}\right)=.089-.120 \log \left(R e_{p}\right) \text { for } R e_{p} \leq 5.6
$$

$P_{\text {om }}$ is the corrected model predicted Pitot pressure which is to be compared directly with the experimental data. $P_{\text {oy }}$ and $R e_{p}$ are, respectively, the model calculated values for the pressure behind the shock wave and the Reynolds number. The Reynolds number, $R e_{p}$, was calculated utilizing the following relation

$$
R e_{p}=\rho_{-} U_{-} D_{p} / \mu
$$

where $\rho_{-}$and $U_{-}$are the gas density and velocity of the freestream preceding the shock, whereas $D_{p}$ and $\mu$ are, respectively, the probe diameter and the viscosity at stream temperature, $T_{p}$ behind the shock wave. The temperature, $T_{r}$ was computed from the normal-shock relation for static temperature (See Ref. 9, p. 118). Once, $T_{n}$ was known, then the viscosity, $\mu$, was determined from the power-law relating viscosity of gases (See Ref. 1, p. 6) by the following formula

$$
\mu=\mu_{\text {rew }}\left(T_{y} / T_{\text {ret }}\right)^{n}
$$

where $\mu_{\text {rat }}$ is the value of the viscosity at the reference temperature, $T_{\text {rets }}$, and $n=0.75$.

\section{Direct Comparison of Flow Angle and Pressure with Experimental Data}

To compare the model predictions with the experimental data, the pressures and flow angles at the grid points in Fig. 1 were linearly interpolated to pressures and flow angles along the three radial lines at axial positions of $12 \mathrm{~mm}, 36 \mathrm{~mm}$, and $120 \mathrm{~mm}$ as shown in Fig. 1 .

Results of the comparisons at these three axial positions for pressure as a function of radial distance is shown in Fig. 7. Results for the flow angles are given in Fig. 8 for the $12-\mathrm{mm}$ and $120-\mathrm{mm}$ axial positions since there was no reliable experimental data at the $36-\mathrm{mm}$ axial position. In general there is excellent agreement between the model predictions and the experimental data. The biggest variation between the model predictions and the experimental data is at the $12-\mathrm{mm}$ axial position for both the pressure and the flow angle where the experimental data are not as precise. 


\section{Concluding Remarks}

A kinetic theory model was used to calculate flow parameters external to a low-thrust axisymmetric nozzle. The model predictions for flow angle and pressure were compared for the first time with experimental data taken for identical flow conditions. Agreement between the model predictions and the experimental data was very good, which gives one confidence that the model and numerical techniques used to calculate the flowfield parameters may be useful in calculating flows from other lowthrust nozzles. In particular, the model could be used to calculate the flowfield parameters under space conditions that would be prevalent around the space station being built by the United States. Preliminary model calculations using space conditions look promising.

\section{Acknowledgments}

This work was performed with the support of NASA-Lewis research Center under Grant NAG 3-746.

\section{References}

'Penko, P .F., Boyd, I. D., Meissner, D. L., and DeWitt, K. J., "Pressure Measurements in a Low Density Nozzle Plume for Code Verification," AIAA Paper 91-2110, AIAA/SAE/ASME/ASEE 27th Joint Propulsion Conference, Sacramento, CA., June 1991.

2Riley, B. R., and Scheller, K. W., "Kinetic Theory Model for the Flow of a Simple Gas from a Two-Dimensional Nozzle," Rarefied Gas Dynamics. Space Related Studies, edited by E. P. Mutz, D. P. Weaver and D. H. Campbell, Vol. 116, Progress in Astronautics and Aeronautics, AlAA, Washington D. C., 1989, pp. $352-$ 362.

${ }^{3}$ Riley, B. R., "Kinetic Theory Model for the Flow of a Simple Gas from a Three-Dimensional Axisymmetric Nozzle," Rarefied Gas Dynamics Proceedings of the 17th Intemational Symposium on Rarefied Gas Dynamics, Aachen, Germany, 1990, edited by A.E. Beylic, VCH Publishers, New York and Germany, 1990, pp. 291-298.

4Patterson, D. G., Introduction to the Kinetic Theory of Gas Flows, University of Toronto Press, Toronto, Canada, 1971.

sAnderson, D. G., "On the Steady Krook Kinetic Equation: Part 1," Journal of Fluid Mechanics, Vol. 26, Pt. 1, Sept. 1966, pp. 17-35.

-Boyd, I. D., Private Communication, Eloret Institute, NASA Ames Research Center, Moffett Field, CA., June 1991.

'Boyd, I. D., Penko, P. F., and Camey, L. M., "Efficient Monte Carlo Simulation of Rarefied Flow in a Small Nozzle," AIAA Paper 90-1693, AIAAASME 5th Joint Thermophysics and Heat Transfer Conference, Seattle, WA., June 1990.

-Penko, P. F., Boyd, I. D., Meissner, D. L., and DeWitt, K. J., "Measurement and analysis of a Small Nozzle Plume in Vacuum," to be published in J. Propulsion and Power.

-Shapiro, A. H., The Dynamics and Themodynamics of Compressible Fluid Flow, Ronald Press, New York, 1953, pp. 153-154.

10Stephenson, W. B., "Use of the Pitot Tube in Very Low Density Flows," AEDC-81-11, Amold Engineering Development Center, Oct.1981. 


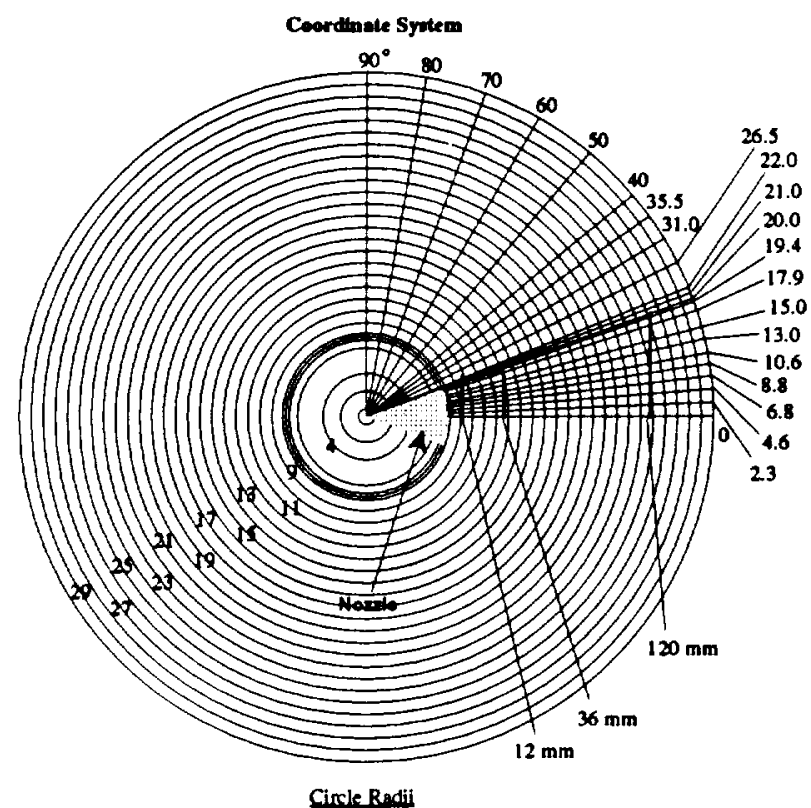

$\begin{array}{rrrrrrrrrr}1 & 0 \mathrm{~mm} & 7 & 46.4 \mathrm{~mm} & 13 & 82.1 \mathrm{~mm} & 19 & 123.7 \mathrm{~mm} & 25 & 165.3 \mathrm{~mm} \\ 2 & 4.6 \mathrm{~mm} & 8 & 47.4 \mathrm{~mm} & 14 & 89.0 \mathrm{~mm} & 20 & 130.7 \mathrm{~mm} & 26 & 172.3 \mathrm{~mm} \\ 3 & 14.8 \mathrm{~mm} & 9 & 34.4 \mathrm{~mm} & 15 & 96.0 \mathrm{~mm} & 21 & 137.6 \mathrm{~mm} & 27 & 179.2 \mathrm{~mm} \\ 4 & 25.0 \mathrm{~mm} & 10 & 61.3 \mathrm{~mm} & 16 & 103.0 \mathrm{~mm} & 22 & 144.5 \mathrm{~mm} & 28 & 186.1 \mathrm{~mm} \\ 5 & 39.8 \mathrm{~mm} & 11 & 68.2 \mathrm{~mm} & 17 & 110.0 \mathrm{~mm} & 23 & 151.5 \mathrm{~mm} & 29 & 193.1 \mathrm{~mm} \\ 6 & 45.4 \mathrm{~mm} & 12 & 75.2 \mathrm{~mm} & 18 & 116.8 \mathrm{~mm} & 24 & 158.4 \mathrm{~mm} & 30 & 200.0 \mathrm{~mm}\end{array}$

Fig. 1 Grid system. Grid points are at Intersections of the radil and clrcular lines. All grld points are in the $y=0$ plane. The llnes marked as $12 \mathrm{~mm}, 36 \mathrm{~mm}$, and $120 \mathrm{~mm}$ are the radial lines along which experimental data was compared to the predictions of the model. The nozzle llp is at radius $46.4 \mathrm{~mm}$ and angle of $20^{\circ}$.

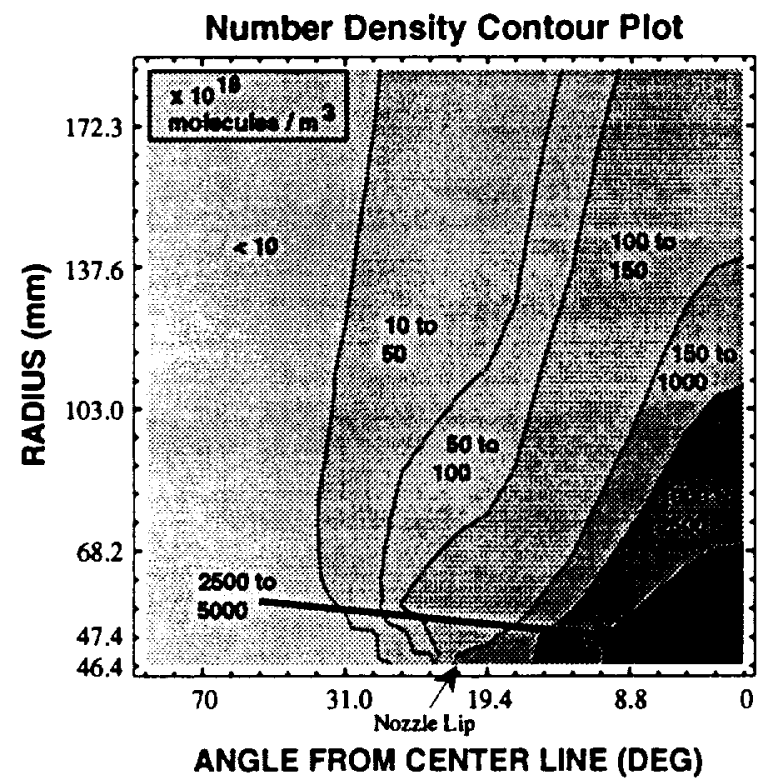

Fig. 2 Number density contour plot for flowtield shown in Fig.1. 


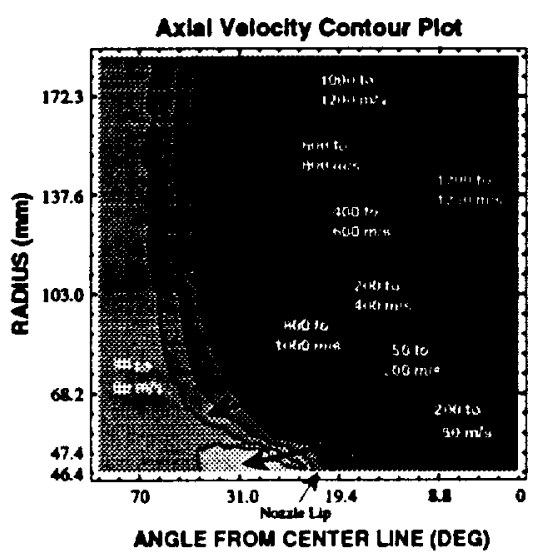

Fig. 3 Axlal veloclty contour plot for flowfleld shown in Fig. 1.

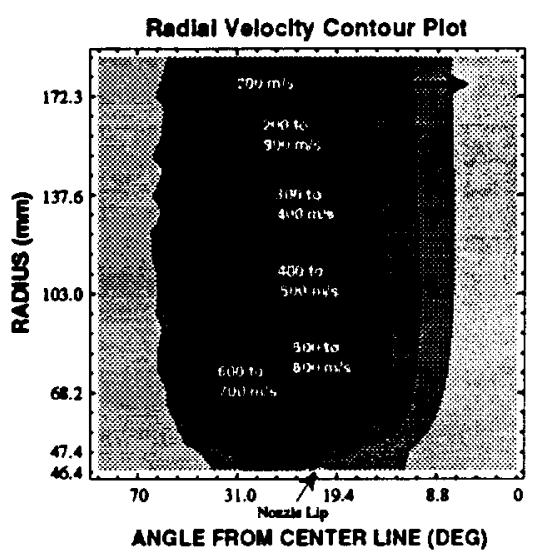

Fig. 4 Radial velocity contour plot for flowfield shown in Fig. 1.

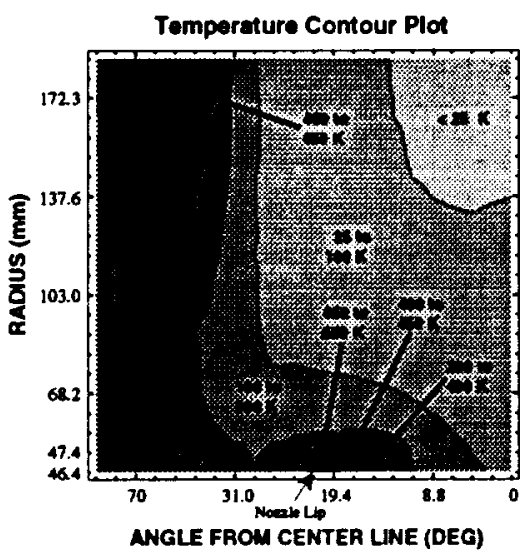

Fig. 5 Temperature contour plot for flowfield shown in Fig. 1.

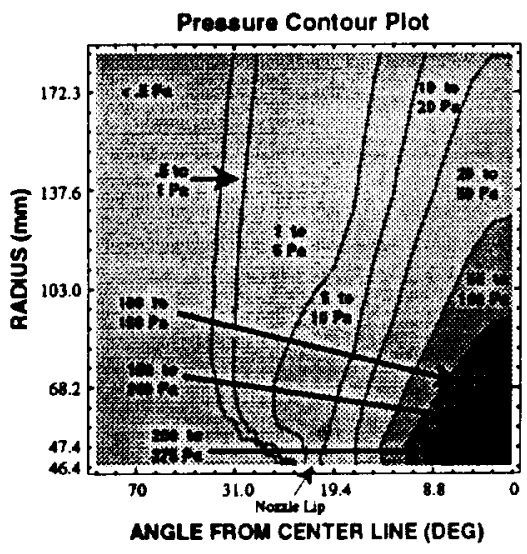

Fig. 6 Pressure contour plot for flowfield shown in Fig. 1. 


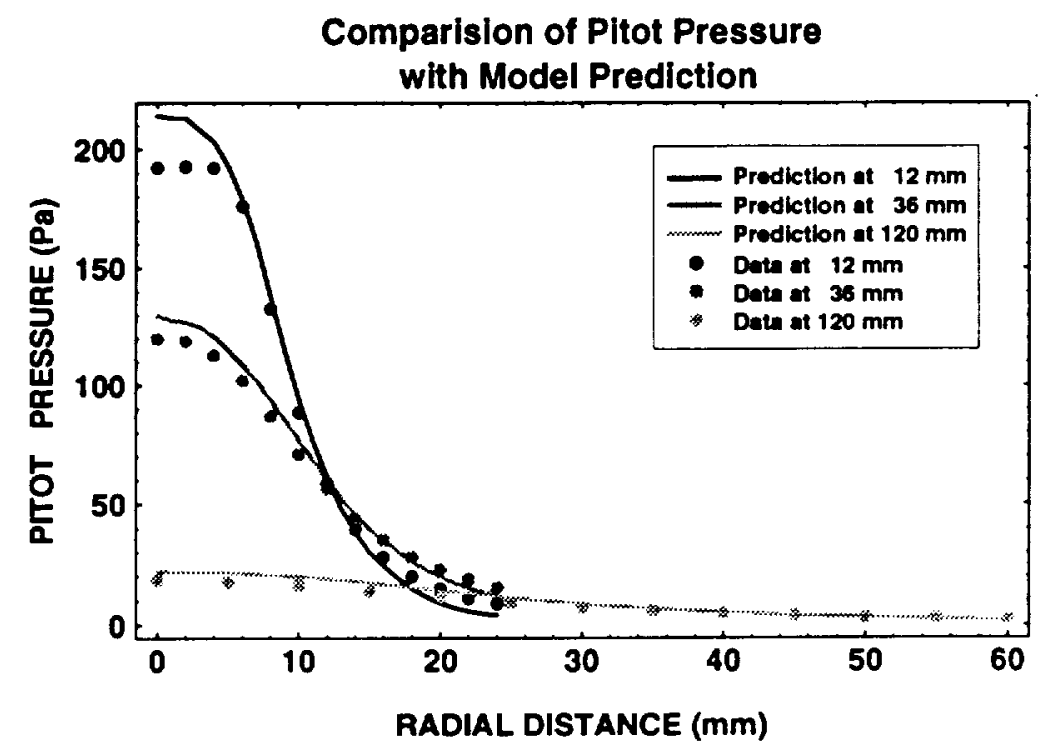

Fig. 7 Comparison of experimental Pltot pressures and model prediction at three axial positions. The last radial data polnt at each axial position corresponds to the end of the approprlate line In Fig. 1.

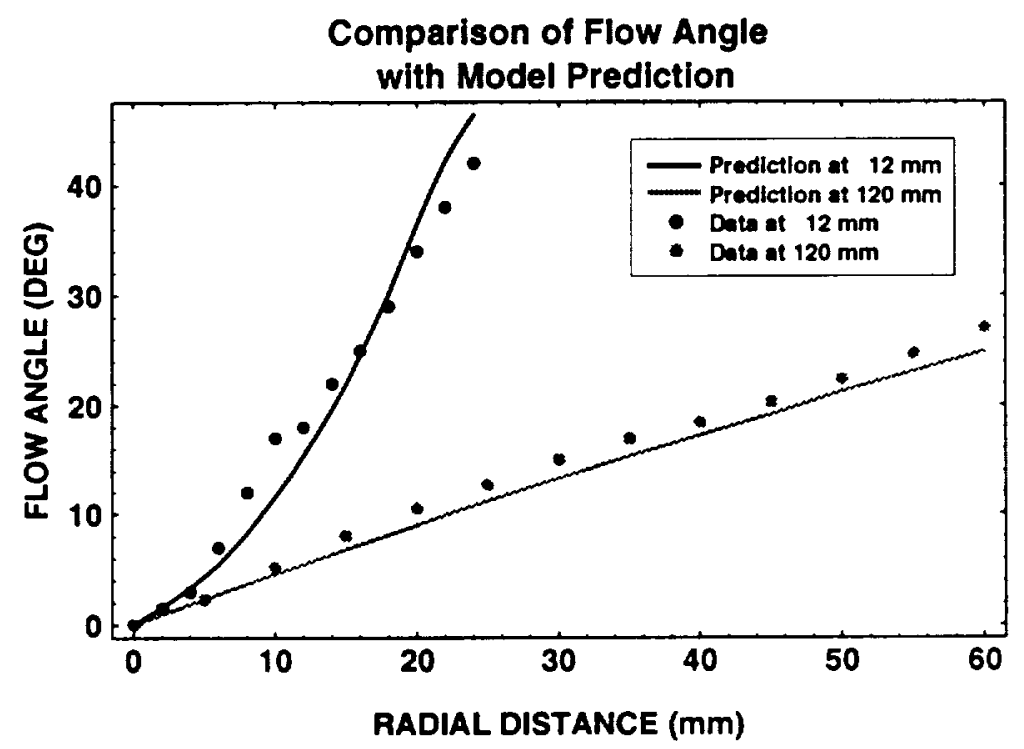

Fig. 8 Comparlson of experimental flow angles and model predictions at two axial positions. The last radial point at each axial position corresponds to the end of the appropriate line In Fig. 1. 


\begin{tabular}{|c|c|c|c|c|c|}
\hline $\begin{array}{c}\text { Angle } \\
\text { (Degrees) }\end{array}$ & $\begin{array}{l}\text { Rodia! } \\
\text { Volocity } \\
\text { (m/o) }\end{array}$ & $\begin{array}{c}\text { Axial } \\
\text { Velocthy } \\
\text { (m/s) }\end{array}$ & $\begin{array}{c}\text { Temparature } \\
\text { (K) }\end{array}$ & $\begin{array}{l}\text { Number } \\
\text { Density } \\
\text { (Moleculoes } \mathrm{m}^{3} \text { ) }\end{array}$ & $\begin{array}{c}\text { Pltot } \\
\text { Preasura } \\
\text { (Pa) }\end{array}$ \\
\hline \begin{tabular}{r|}
0.0 \\
2.3 \\
4.6 \\
6.8 \\
8.8 \\
10.6 \\
13.0 \\
13.0 \\
15.0 \\
17.0 \\
19.4 \\
20.0
\end{tabular} & $\begin{array}{r}0.0 \\
35.0 \\
66.8 \\
99.6 \\
140.0 \\
174.0 \\
215.0 \\
233.0 \\
237.0 \\
218.0 \\
135.0\end{array}$ & $\begin{array}{r}1180 \\
1170 \\
1140 \\
1120 \\
1070 \\
997 \\
859 \\
732 \\
525 \\
415 \\
339\end{array}$ & $\begin{array}{r}99 \\
99 \\
102 \\
115 \\
148 \\
201 \\
278 \\
338 \\
421 \\
467 \\
536\end{array}$ & $\begin{array}{l}4.46 \mathrm{E}+21 \\
4.51 \mathrm{E}+21 \\
4.62 \mathrm{E}+21 \\
4.30 \mathrm{E}+21 \\
3.36 \mathrm{E}+21 \\
2.42 \mathrm{E}+21 \\
1.53 \mathrm{E}+21 \\
1.13 \mathrm{E}+21 \\
7.43 \mathrm{E}+20 \\
6.30 \mathrm{E}+20 \\
6.01 \mathrm{E}+20\end{array}$ & \begin{tabular}{r|}
272.0 \\
269.0 \\
262.0 \\
237.0 \\
173.0 \\
116.0 \\
61.2 \\
36.9 \\
16.4 \\
11.0 \\
9.2
\end{tabular} \\
\hline
\end{tabular}

